\title{
Fan Culture under the Influence of Media Development
}

\author{
Zixuan Liao \\ Communication University of China, Beijing, China \\ Email: liaotaonina@qq.com
}

How to cite this paper: Liao, Z. X. (2021). Fan Culture under the Influence of Media Development. Open Journal of Social Sciences, 9, 88-93.

https://doi.org/10.4236/jss.2021.912007

Received: November 10, 2021

Accepted: December 4, 2021

Published: December 7, 2021

Copyright $\odot 2021$ by author(s) and Scientific Research Publishing Inc. This work is licensed under the Creative Commons Attribution International License (CC BY 4.0).

http://creativecommons.org/licenses/by/4.0/

\begin{abstract}
In the Legacy media era, the power and rights to produce and distribute all cultural products was in the hands of the mass media, with media professionals effectively exercising control and monopoly over audiences through the production and distribution of cultural products, and the power of fans of cultural products was very limited. Recent years, media technology is developing in the direction of digitisation and intelligence. It seems that fans in the mainland of China have dramatic changes. The status of fan culture in Mainland China today will be systematically analyzed in this paper.
\end{abstract}

\section{Keywords}

Fans Culture, Media Development, Fan Communities

\section{Introduction}

In recent years, media technology is developing in the direction of digitisation and intelligence, which makes people's living environment, state of being and consumption patterns have changed to a large extent. From the perspectives of communication, it is gradually moving from the traditional media era to the new media era. The role of the audience has changed dramatically because of the rapid development of media technology, and the boundary between the consumer and producer has become increasingly blurred. Fans are part of the audience. Fans can be defined to some audience who has a fervent devotion to an actor, celebrity, television programme or other textual form portrayed by the mass media (Lewis, 1992). In short, they are a group of people who devote their time and emotion to an idol or a film, TV show or novel or comic book. They regard these cultural products as spiritual belief.

Legacy media is the media that is considered "traditional" such as radio, tele- 
vision, and especially newspapers. With legacy media, the audiences do not interact with the content and stay in a totally passive position. Mass media almost hold all the rights to produce and distribute all cultural products. In fact, the legacy media wielded a certain amount of power in the past. These cultural industry professionals effectively control and monopoly over their audiences through the dissemination of cultural products. The media may have been an indirect instrument of domination over society to some extent. Audiences only can be regard as receivers at that time. Fans, which can be called "active audiences", have a desire and a constant struggle for the power.

However, the essential structural changes of historical processes of society are now taking place very rapidly because of the development of media technology. So it has also led to a dramatic change in the expression and behaviour of fans. In a way, they seem to be gaining more power over the discourse. This paper tries to analyze the changing logic of obsession and expression of Chinese fans under the influence of new media technologies. This study draws the following conclusions through network participatory observation on fans communities on popular network platforms in China, such as Sina MicroBlog (Weibo).

\section{Fans Gain More Power and Rights}

As we all known, McLuhan believed that the age of digital media could eradicate many of the weakness of industrial society. With the help of digital media, the fans' desire for power indeed is more than satisfied. However, the advent of the new media age will help break the old media's grip on audiences seems a little over-optimistic. Although fans have gained more power as a result of media technology, the relationship between fans and the cultural industry cannot be simply explained by resistance or incorporate. Nowadays, the cultural industry and the fans rule the media ecosystem together, and the power relationship is ambiguous and complex. The types of fans have also become more complex: passive fans, resistant fans, fans that actively produce and disseminate derivative works to attract citizens to be fans are all part of the fans.

Fans gain more power shown in two sides: firstly, they have become more active in producing and distributing derivative work on the internet by their selves; secondly, they have more ways to communicate with the cultural industry.

On the one hand, Users enjoy a considerable degree of autonomy and freedom of action because of social media. In other words, the emergence of new media has made audiences more active and has given them the power and freedom to express themselves. The new media has also empowered the citizens to actively blur the boundaries between the producer and the consumer. They have been given the ability to produce and distribute content with the help of digital technology.

In the past, traditional media has primarily been speaking with one voice. When mass media convert to de-center transmission network, consumers are dissolving the monopoly and hegemony of traditional media. Obviously, Fans are able to create and share their ideas and re-creations on the internet. Fans ac- 
tively use cultural products to create a secondary art works, performing them online in order to create self-idealized identities and characters. At the same time, these behaviors also exhibit the characteristics of the play theory of mass communication. According to the psychologist William Stephenson (Stephenson, 1988), in addition to communication as work, there is a kind of communication that goes beyond the utilitarian and is only for the pleasure of the self. Such communication is allowing people to be immersed in active play. That is the reason why many fans enjoy communicating with each other on the internet. Fans' comments can even become part of the work through Danmu, which also can be called Bullet screen. Bullet screen is a popular feature on online videos in China, which allows viewers to post real-time comments on the screen while watching a film or a talk show. That is to say, all the comments become an essential part of the culture products. These comments are not even carefully thought out, but are made because of a sense of instant pleasure.

This has inevitably led to a shift away from "elegant" and elitist cultural production and towards a "populist" approach. On the positive side, the derivative work enriches the cultural production itself, perpetuating its life and expanding its influence. For example, many fans created their own conceived ending plots for the cartoon Doraemon, showing great imagination and creativity and awakening potential fans to the cartoon and related cultural products.

On the other hand, the creators of cultural products are in some cases at the mercy of commercial capital, and in some cases they are controlled by their fans. For example, Tencent produced the talent show Produce 101, the first female group idol talent show in China. The show quickly became popular after it aired. The show amplifies the power of fans by allowing them to vote online to determine the ranking of contestants and win or lose. Fans can vote for the contestants through various platforms such as DOKI, Tencent Video's self-created platform, and Sina MicroBlog (Weibo). DOKI has become an essential medium for expanding the power of fans. Fans can form a community of fans on this platform, bringing them closer to their idols.

\section{The Internet-Based Fan Community}

With the help of digital technology, people have built a new online social form based on the Internet. The former group structure, based on blood and clan, is gradually being dismantled and communities are being created on the internet. As Maffesoli (Maffesoli, 1996) describes this phenomenon in his book The Age of the Tribe. He states that the tribe of our time is no longer the primitive community with its emphasis on religious values as Turgot believed, but a postmodern aesthetic way of grouping together. Nowadays, fans are keen on find eachother and form groups through the internet. Rhiannnon Bury (Bury, 2017) argued that although social media gives some pleasure to participatory fans, they are not able to interact deeply and therefore do not form a fan base. However, as far as I am concerned, her view may be biased. In recent years, fans 
in the mainland of China have formed a certain cohesive fan community on platforms such as Baidu posting, Sina MicroBlog (Weibo) and WeChat groups.

Because of the emergence of social networks, fans have also found an effective way to set up compartments for their circles as well. They use special linguistic symbols to define the boundaries of their fans group. These linguistic symbols not only establish a common space of meaning for fans, but also make those who do not belong to the group the "other". These discursive systems become the default rules of the fan community, allowing for a greater sense of cohesion and belonging among fans. Social identity is the awareness that an individual is a member of a particular social group, and that the awareness of belonging to a particular group brings unique emotions and values to the individual. (Tajfel \& Turner, 1986)

In today's the mainland of China, fans who share common emotions form their own tribes and circles on various Internet platforms. Fan communities do not have a very stable structure. Fans can move around in different fan groups and no one has absolute loyalty. All fans are enjoying the temporary identity on the internet. Therefore, the relationship between the individual fan and the fan community is therefore fluid. The internet gives fans a virtual identity, allowing them to join and leave more freely. Just as there is a fan who can be a fan of Harry Potter, he can also be a fan of the Korean girl group Blackpink, and they can join and leave with relative ease.

Rheingold (Rheingold, 2003) states that the internet helped internet users to produce better mechanisms for effective collaboration. The power of offline groups is not comparable to the power of today's clusters of fans. Because of the upgrading and advancement of the medium, fans on social media platforms are more likely to be brought together by shared emotions and sentiments. Their gathering tends to create the emotional consensus, and the collective identity that comes with the coming together of a group can quickly heat up this emotional consensus. However, there is also a danger that, in this emotional atmosphere, fans can also use the clustering of fan circles to achieve discursive hegemony.

For example, fans often use the "hottest topics" and "most searched hashtags" in Sina MicroBlog (Weibo) as an important arena for discourse. Fans love to create the illusion that an idol is very popular by repeatedly posting a lot for that idol, and attacking and covering up any comments that hurt their idol. The virtual high popularity affects the fairness of the actor-singer industry and even creates a false popularity of some poor quality artists, which has a bad effect on the healthy growth of teenagers. Star Wu Yifan has been arrested for a crime, but some of his fans have banded together to repeat a lot of inappropriate comments in an attempt to cover up the crime of their inferior idol.

\section{The Extension and Development of the Fan Economy}

The change in the medium has also allowed for a more diverse business model 
for the cultural product industry. In the past, fans used to consume through the regularly purchase of posters, records or tickets to concerts. In the recent years, social networking platforms, such as Sina MicroBlog (Weibo), impose a set of values on their followers in relation to traffic data. This means that celebrities who get the highest number of searches and readings on online platforms have a higher status. Fans will volunteer to work as unpaid laborers so that their idols can win the contest. The star who with a huge fan base also means more commercial resources and performance opportunities. For example, Idol Yiyang Qianxi's fans cooperate with bloggers on Sina MicroBlog (Weibo), Douban and many other social platforms through online gathering. Fans sent film tickets to these online opinion leaders to raise awareness of Yiyang Qianxi's Film Better Days. According to maoyan APP (a leading film information platform in China), pre-sales boxoffice of this film have already exceeded 100 million yuan before its release.

It also shows a shift in the way fans consume cultural products, with fans repeatedly buying online digital cultural products in large quantities to help boost the commercial value and influence of celebrities. They display their consumption credentials on social networks. Consumption has become an effective way for fans to prove their emotions and gain the emotional identity of the community. The fan communities formed by relying on social networks are also extended to become consciously and deeply involved in the cultural product industry chain. It is easy to see that the fan economy is heavily reliant on social networks. The value and influence of a celebrity idol or cultural product is expanded through the consumption of the idol's brand by fans and the spontaneous production and distribution of content by fans. In business logic, this expanded influence means greater access to brands and greater market value. The medium has changed, and fans are being actively turned into digital labour.

\section{Conclusion}

The constant advancement of the medium has made the audience less of a mere recipient. Fans who have a certain level of fascination with cultural products have also updated their consumption patterns of media content. They are not just passive viewers and followers. They now have a degree of initiative. They are active in the production and dissemination of texts. They do not hide their desire to have a voice. Social networks give fans the space for random expression and the freedom to create and disseminate their own creations. Fans create and distribute their own texts in a playful way. However, the behavior of fans perpetuates the life of cultural products and increases their influence.

Because of the popularity of the internet, the way in which fans gather has also changed. The former group structure based on blood and clan has been gradually dismantled, and communities have been created through the internet. Online communities have become an important area for fans to communicate their feelings. Because of their virtual identity on the internet, fans are disloyal. In the 
meantime, fans are brought together by emotional consensus, and online fan communities have cohesion and stability.

The development of the medium has led to the rise of the fan economy as well. The new medium has given rise to new modes of cultural consumption and new popularity indicator. Platform technology allows fans' love to be quantified. However, the convenience of the Internet may make fans' behaviors tend to be irrational, such as excessive purchase.

This paper suggests that the current Chinese fan culture should not be viewed with the logic of the past. Today's fan culture displays greater collective action. Fans' treatment of their favorite idols is not just a matter of emotional projection. The fan community is a competitive arena in which fans are disciplined all the time. Under the influence of technical logic and commodity logic, fans tend to fall into the group irrational cognitive state. Fans seem to be empowered by technology, but they can also be gripped by a collective unconscious that needs to be guarded and concerned about.

\section{Conflicts of Interest}

The author declares no conflicts of interest regarding the publication of this paper.

\section{References}

Bury, R. (2017). Technology, Fandom and Community in the Second Media Age, Convergence. The International Journal of Research into New Media Technologies, 23, 627-642. https://doi.org/10.1177/1354856516648084

Lewis, L. A. (Ed.) (1992). The Adoring Audience: Fan Culture and Popular Media. Routledge.

Maffesoli, M. (1996). The Time of The Tribes: The Decline of Individualism of Mass Society. Trans by D. Smith, Sage.

Rheingold, H. (2003). Smart Mobs: The Next Social Revolution. Perseus Publishing. https://doi.org/10.3917/soc.079.0075

Stephenson, W. (1988). The Play Theory of Mass Communication. Transaction Books.

Tajfel, H., \& Turner, J. C. (1986). The Social Identity Theory of Intergroup Behavior. In S. Worchel, \& L. W. Austin (Eds.), Worchel, Psychology of Intergroup Relation (pp. 7-24). Nelson-Hall. 